\title{
Effects of NELL2 on the regulation of GnRH expression and puberty in female rats
}

\author{
S.S. Zhou and P. Li \\ Department of Endocrinology, Shanghai Children's Hospital, \\ Shanghai Jiao Tong University, Shanghai, China
}

Correspondence author: P. Li

E-mail: lipin21@126.com

Genet. Mol. Res. 13 (3): 6672-6682 (2014)

Received February 19, 2014

Accepted July 26, 2014

Published August 28, 2014

DOI http://dx.doi.org/10.4238/2014.August.28.12

\begin{abstract}
Neural tissue-specific epidermal growth factor-like repeat domain-containing protein (NELL2) was previously found to play an important role in nerve growth, neural differentiation, neural elasticity, synaptic transport, and vesicle release. In this study, we examined the effect of NELL2 on gonadotropin-releasing hormone $(\mathrm{GnRH})$ neurons and the initiation of puberty in female rats. We studied changes in NELL2 mRNA and protein expression at different stages of sexual development (postnatal days 30,35, and 45) in female rats to determine the impact of NELL2 on GnRH mRNA expression. We also investigated the influence on the vulva-opening age by inhibiting NELL2 mRNA expression through lentiviral vector-mediated RNA interference. The intraventricular administration of an NELL2interfering virus reduced NELL2 and GnRH expression at multiple stages of sexual development and delayed the age of vulva-opening in female rats. These results demonstrate that lentiviral-mediated RNA interference technology can be used for targeted regulation of sexual
\end{abstract}


development in vivo. In addition, we found that NELL2 regulated the initiation of puberty in female rats.

Key words: Gonadotropin-releasing hormone; RNA interference; Neural tissue-specific epidermal growth factor-like repeat domaincontaining protein; Puberty

\section{INTRODUCTION}

The mechanism generally accepted as underlying the onset of puberty involves initiation of the hypothalamus-pituitary-gonad axis (Seminara et al., 2006; Terasawa, 2006). During this process, pulsatile gonadotropin-releasing hormone $(\mathrm{GnRH})$ secretions from specialized hypothalamic neurons stimulate hormonal cascades and gonadal activation (Harris and Levine, 2003). Notably, GnRH secretion is affected by nutritional status, heredity, psychological state, circadian cycle, climate, and estrogen-based feedback (Bringer et al., 1999; Palmert and Boepple, 2001). No previous studies have examined the specific mechanism of GnRH neuron activation necessary for puberty initiation.

Recent studies have reported that neural tissue-specific epidermal growth factor-like repeat domain-containing protein (NELL2), a secreted protein containing 6 epidermal growth factor (EGF) sequences, may regulate GnRH secretion and influence sexual development. Ha et al. (2008) reported that the intraventricular administration of antisense nucleotides inhibited NELL2 synthesis in rats. In vitro studies showed that lower levels of NELL2 led to reduced GnRH release from hypothalamic neurons. Previously, we found that hypothalamic NELL2 and $G n R H$ mRNA expression in female rats varied throughout sexual development (Duan and Li, 2010). NELL2 mRNA expression peaked during the pre-pubescent stage, while GnRH levels peaked during early puberty. NELL2 mRNA expression peaked earlier than GnRH mRNA expression. NELL2 may promote the onset of puberty by upregulating $G n R H$ mRNA in GnRH neurons. In this study, we examined possible mechanisms of NELL2-mediated regulation of GnRH neurons and the effect on the onset of puberty.

\section{MATERIAL AND METHODS}

\section{Construction of lentiviral vector $F U G W-N E L L 2-$ microRNA}

The interference effects of a NELL2-microRNA interference vector (interference sequence: F: 5'-TGCTGTAATCGTCGATTCTGATGTACGTTTTGGCCACTGACTGACGTA CATCAATCGACGATTA-3' and R: 5'-CCTGTAATCGTCGATTGATGTACGTCAGTCAGT GGCCAAAACGTACATCAGAATCGACGATTAC-3') were previously verified in vitro. The interference vector was digested with $X h o \mathrm{I}, P v u \mathrm{II}$, and $\mathrm{NcoI}$ and then ligated into an FUGW vector that had been digested with $X b a \mathrm{I}$. The ligation product was transformed into competent DH5 $\alpha$ cells (Takara; Shiga, Japan). Positive recombinant clones were selected, identified using HindIII and SacII (Takara), and sequenced (Invitrogen; Carlsbad, CA, USA) to obtain the lentiviral interference vector $F U G W$-NELL2-microRNA. The control plasmid was constructed using an F microRNA sequence: 5'-tgctgAAATGTACTGCGCGTGGAGACGTTTTGGCCA CTGACTGACGTCTCCACGCAGTACATTT-3', R: 5'-cctgAAATGTACTGCGTGGAGAC GTCAGTCAGTGGCCAAAACGTCTCCACGCGCAGTACATTTc-3' (Zhou and Li, 2011). 


\section{Lentiviral packaging and titer determination}

Plasmids free of endotoxin were extracted from correctly sequenced clones using a plasmid extraction kit (Qiagen; Hilden, Germany). Packaging plasmids that were free of endotoxin were prepared at the same time. The 293T cells were inoculated during the logarithmic growth phase; cell density was $5 \times 10^{6} / \mathrm{mL}$, and cells were incubated at $37^{\circ} \mathrm{C}$ under $5 \% \mathrm{CO}_{2}$. When the cells reached $60-80 \%$ confluence, they were transfected with $\mathrm{CaPO}_{4}$ in accordance with the Promega ProFection Kit manual (Promega; Madison, WI, USA). The virus preparation system included $16 \mu \mathrm{g} F U G W$-NELL2-microRNA, $12 \mu \mathrm{g} \Delta 8.9$, and $8 \mu \mathrm{g}$ vesicular stomatitis virus $\mathrm{G}(V S V-G)$. After transfection, cells remained in the complete culture solution (Dulbecco's modified Eagle medium containing 10\% fetal bovine serum) for $6 \mathrm{~h}$ and were then incubated for approximately $60 \mathrm{~h}$ at $37^{\circ} \mathrm{C}$ under $5 \% \mathrm{CO}_{2}$. The virus culture supernatant obtained was centrifuged and filtered. After 18,000 $\mathrm{g}$ ultracentrifugation for $1 \mathrm{~h}$, the supernatant was discarded. A small amount of Hanks' liquid was added to the virus precipitate to facilitate subsequent removal of virus-concentrated solution. The same method was applied to prepare control virus using the empty lentiviral vectors $(F U G W)$. Robust $293 \mathrm{~T}$ cells were inoculated on 96-well plates at the same concentration. Lentiviral virus was diluted 10-fold in 3-5 gradients, at which point the cells were infected with the virus. The number of fluorescent cells containing green fluorescent protein was observed and counted by fluorescence microscopy. The titer value of the virus stock solution was calculated as the value obtained divided by the corresponding dilution factor. The formula used to calculate virus titer was $T U / \mu L=(P x$ $\mathrm{N} / 100 \times \mathrm{V}) \times 1 / \mathrm{DF}$, where $\mathrm{P}=\%$ green fluorescent protein-positive cells, $N=$ the number of cells transfected, $\mathrm{V}=$ the volume of virus dilution added to each well $(\mu \mathrm{L})$, and $D F=$ dilution factor $=1$ (undiluted), $10^{-1}($ diluted $1 / 10)$, and $10^{-2}($ diluted $1 / 100)$.

\section{Animals}

Ninety homologous, female, specific-pathogen-free-grade (21 days after birth, weighing 40-50 g) Sprague-Dawley rats were provided by Sino British SIPPR/BK Lab Animal Ltd. (Shanghai, China). The rats were randomly assigned to 3 experimental groups $(\mathrm{N}=30)$ and were injected intracerebroventricularly with saline (group A), blank virus (group B), or interfering virus (group C). Animals were maintained in 12-h light/dark conditions, with lighting beginning at 7:00 am, and the temperature was maintained at approximately $21^{\circ} \mathrm{C}$ in concordance with the National Institutes of Health Guidelines for the Care and Use of Laboratory Animals. All animals were given free access to rat chow and water. The study protocol was approved by the Institutional Animal Care and Use Committee of Shanghai, China.

\section{Intracerebroventricular administration}

Postnatal 21-day-old Sprague-Dawley rats were fixed on a stereotaxic apparatus after anesthesia and were induced using chloral hydrate. The skin was incised along the head midline, and the periosteum was scraped to expose the Bregma point. A microsyringe was used to pierce the skull at a $90^{\circ}$ angle, at the point $1.0 \mathrm{~mm}$ from the posterior Bregma point and 0.5 $\mathrm{mm}$ to the right of the midline. The needle was inserted to a depth of $3.5 \mathrm{~mm}$ (A-1.0, R0.5, $\mathrm{H3} .5$ ) and left in place for 5-10 min. The rats were slowly injected with interfering virus (or saline and blank virus as a control), after which the needle was retained for another 5-10 min. 
After the needle was removed, the skin was closed using sutures.

\section{Tissue preparation}

Ten of 30 animals in each group were randomly chosen and sacrificed on postnatal days (PND) 30, 35, and 45 for fluorescence quantitative polymerase chain reaction (PCR) and western blot analysis. The samples were obtained at 8:00-10:00 am. Intraperitoneal anesthesia was induced using $10 \%$ chloral hydrate $(0.3 \mathrm{~mL} / 100 \mathrm{~g})$, and then the animal was guillotined. The brains were quickly removed and frozen on dry ice. The hypothalamus of each animal was separated and stored at $-80^{\circ} \mathrm{C}$ until use.

\section{Real-time quantitative PCR (RT-PCR)}

Total RNA was extracted from the hypothalamus of each group of rats and then reverse-transcribed into cDNA using a kit from Invitrogen. RT-PCR was performed using the SYBR Green PCR Kit (Takara). The reaction conditions were as follows: $95^{\circ} \mathrm{C}$ for $3 \mathrm{~min}$, $\left(95^{\circ} \mathrm{C}\right.$ for $30 \mathrm{~s}, 59^{\circ} \mathrm{C}$ for $\left.30 \mathrm{~s}\right) \times 40$ cycles, with the acquisition of fluorescence set at $59^{\circ} \mathrm{C}$. The wavelength used for fluorescence detection was FAM $510 \mathrm{~mm}$. The upstream and downstream primers used to amplify the NELL2 gene were: 5'-GGCTCCAGCGTACGTGGAT-3' and 5'-ATGAGACTCGGGGCAATCTA-3'. The upstream and downstream $\beta$-actin primers used as reference were 5'-GTCAGGTCATCACTATCGGCAAT-3' and 5'-AGAGGTCTTTACGG ATGTCAACGT-3'.

\section{Western blot analysis}

The hypothalamus was dissolved in T-PER tissue lysis buffer (Pierce Chemical Co.; Rockford, IL, USA) for protein extraction; 5X sodium dodecyl sulfate buffer solution was added at a ratio of $5: 1$ and the samples were denatured at $95^{\circ} \mathrm{C}$ for $10 \mathrm{~min}$. Luminescence was determined using $20 \mu \mathrm{g}$ protein samples on a $10 \%$ polyacrylamide gel (Bio-Rad Laboratories; Hercules, CA, USA), and subjected to $120 \mathrm{~V}$ constant voltage sodium dodecyl sulfate electrophoretic separation. A $100-\mathrm{V}$ constant voltage was used to transfer the samples to a polyvinylidene fluoride membrane (Bio-Rad Laboratories), which was incubated with the following antibodies: NELL2 anti-rabbit NELL2 (1:1000; Santa Cruz Biotechnology; Santa Cruz, CA, USA) and antirabbit secondary antibody (1:2000; Amersham Biosciences; Amersham, UK). A color-developing solution of chemiluminescence reagent was obtained from Millipore (Billerica, MA, USA).

\section{Data analysis}

The values are reported as means \pm standard error for each group. The Student $t$-test was used for data analysis.

\section{RESULTS}

\section{Identification of lentiviral vector $F U G W$-NELL2-microRNA}

HindIII and SacII were used to enzymatically digest the viral interference vector. En- 
zyme digestion with HindIII yielded 5 bands that were 5030, 1726, 1202, 965, and 556 base pairs in length. Digestion with SacII yielded 2 bands that were 7416 and 2647 base pairs in length. These results were consistent with the expected values (Figure 1). The sequencing results further confirmed that the cloned sequence was correct.

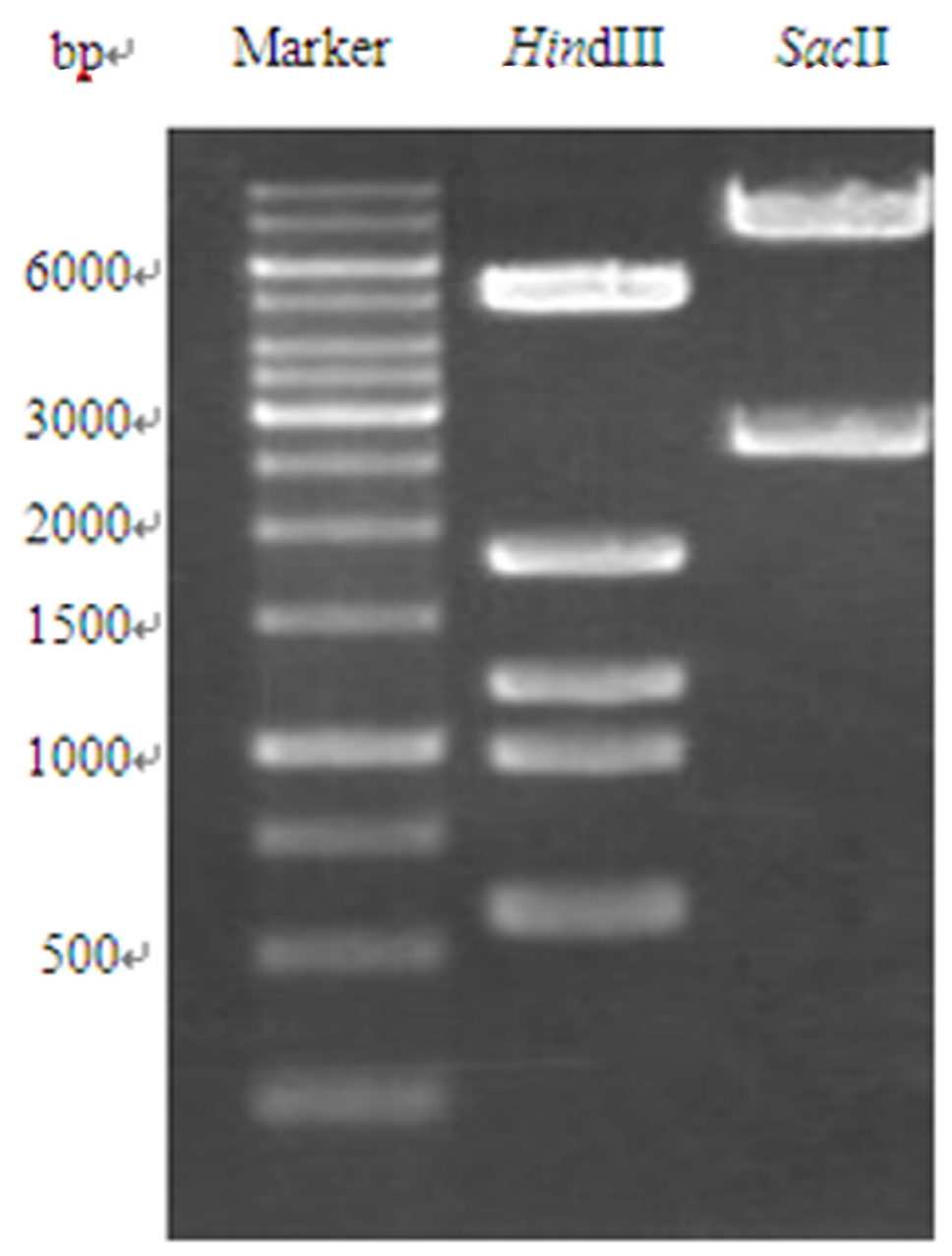

Figure 1. Restriction map of lentiviral vector $F U G W-N E L L 2$-microRNA.

\section{Titer determination of the lentivirus}

The lentivirus stock solution was diluted by 10 -fold in 4 gradients using the limiting dilution method. The 293T cells were infected with the virus. The number of fluorescent cells containing green fluorescent protein was observed and counted by fluorescence microscopy. According to the equation for the virus titer, the titer of lentivirus FUGW-NELL2-microRNA was $1 \times 10^{9} \mathrm{TU} / \mathrm{mL}$ (Figure 2). 

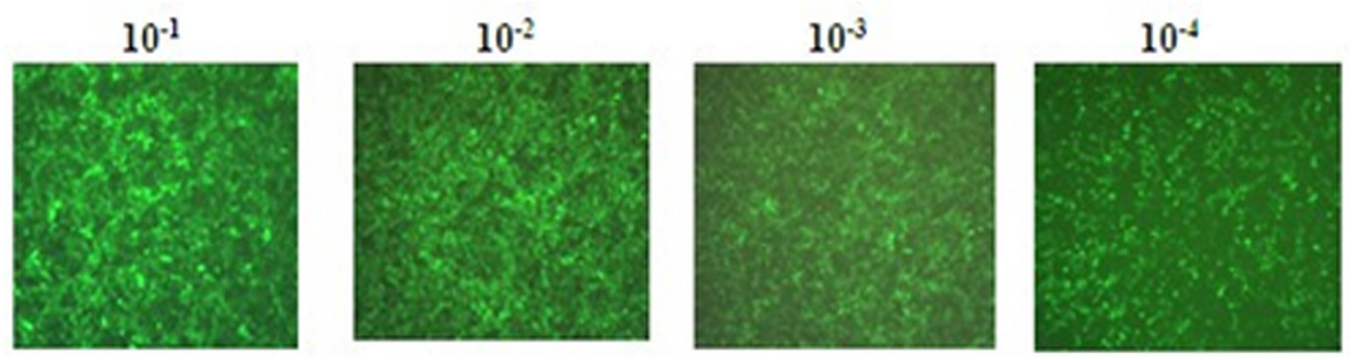

Figure 2. Green fluorescent protein expression after $293 \mathrm{~T}$ cells were infected with the virus at 4 different dilution ratios.

\section{NELL2 mRNA expression in the hypothalamus}

After the 3 experimental groups were injected with saline (group A), blank virus (group B), and interfering virus (group C) by intracerebroventricular administration, we detected NELL2 gene expression in the hypothalamus of female rats in each group on PND 30, 35, and 45 using RT-PCR. As shown in Figure 3, NELL2 mRNA expression was lower in groups treated with the interference vector at all 3 time points compared to groups treated with saline or blank virus $(\mathrm{P}<0.05$ or $\mathrm{P}<0.01)$. Differences in the expression of NELL2 mRNA between the saline group and blank virus group were not statistically significant $(\mathrm{P}>0.05)$.

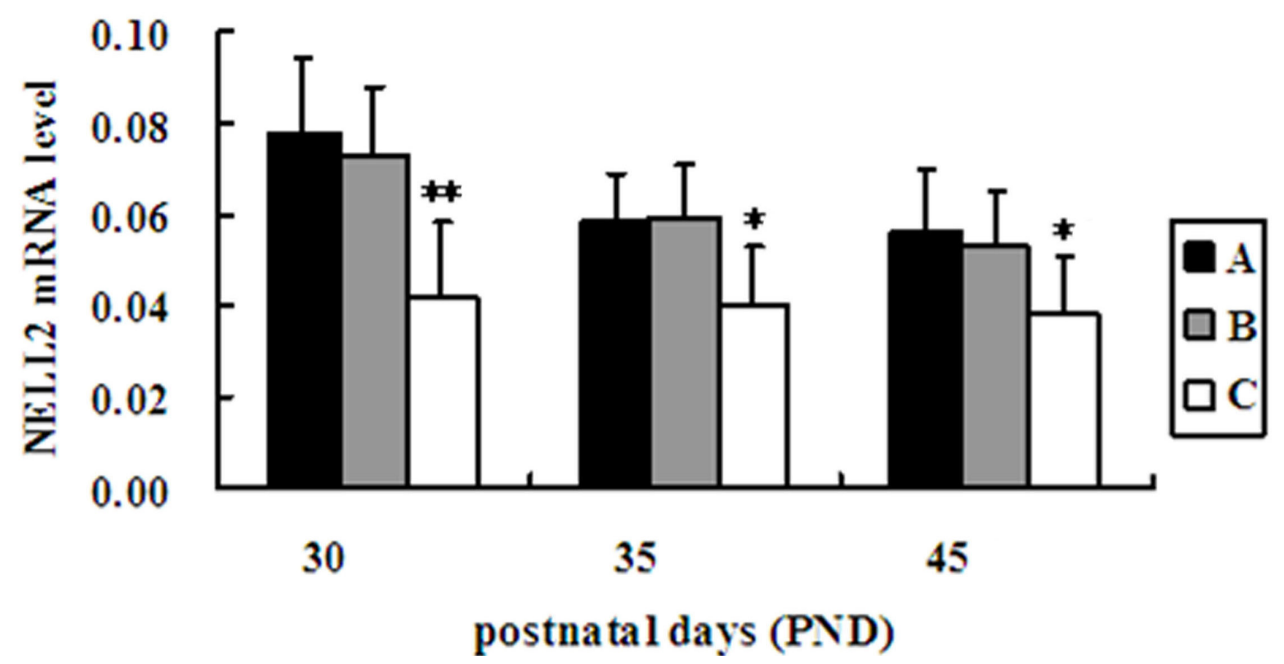

Figure 3. Expression of NELL2 mRNA in hypothalamus at different postnatal days and in different treatment groups of female rats. A, B, and C represent the saline group, blank virus group, and interfering virus group, respectively $(* \mathrm{P}<0.05, * * \mathrm{P}<0.01)$.

\section{Expression of NELL2 in the hypothalamus}

Simultaneously, we detected the level of NELL2 protein in the hypothalamus of female rats by Western blot (Figure 4A and B). Expression of NELL2 protein at all 3 time points 
in the interfering virus group was significantly lower than that in the saline and blank virus groups $(\mathrm{P}<0.05$ or $\mathrm{P}<0.01)$. NELL2 protein expression was similar in the saline and blank virus groups $(\mathrm{P}>0.05)$. NELL2 mRNA expression followed the same pattern as NELL2 protein expression.

A
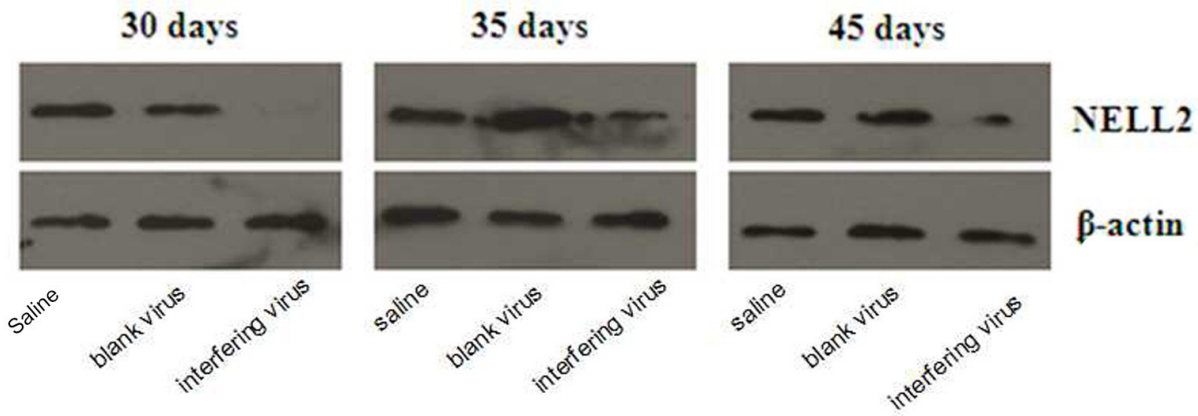

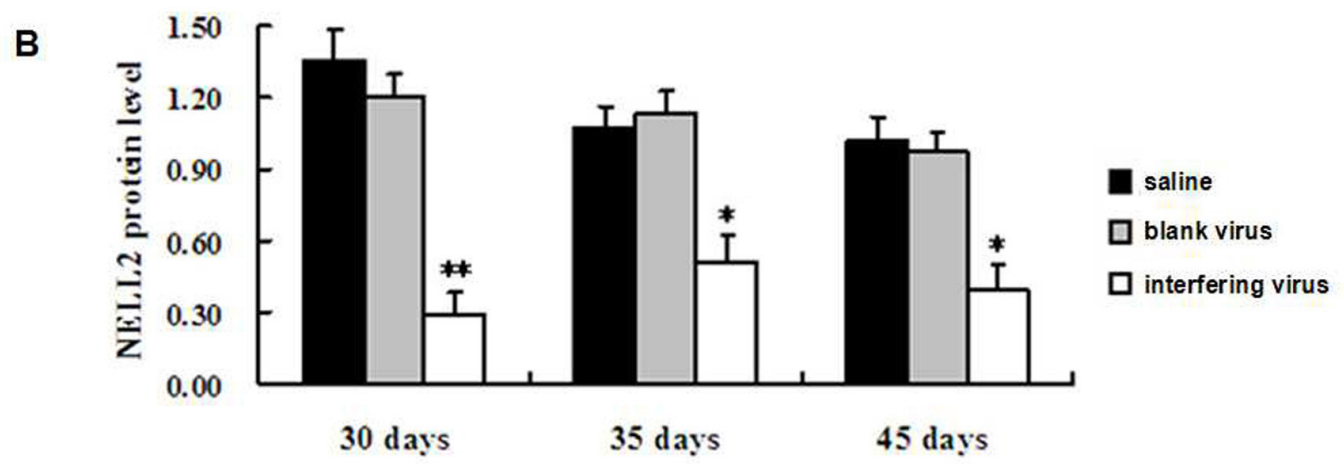

Figure 4. Hypothalamic NELL2 protein expression at different stages of sexual development. A. Protein expression was detected by Western blot. B. Quantitative analysis of protein expression $\left(* \mathrm{P}<0.05,{ }^{*} \mathrm{P}<0.01\right)$.

\section{GnRH mRNA expression in the hypothalamus}

When NELL2 expression was downregulated, GnRH mRNA expression in the hypothalamus at different PNDs and in different treatment groups of female rats was detected (Figure 5). In addition, the GnRH mRNA level was significantly lower in animals treated with the interference vector at PND 30 and PND $35(\mathrm{P}<0.05, \mathrm{P}<0.01)$, but not at PND 45 (P $>$ $0.05)$. The difference in $G n R H$ mRNA expression between the saline group and blank virus group was not statistically significant $(\mathrm{P}>0.05)$.

\section{Age of vulva opening in female rats}

Vulva opening was examined from PND 22 onward. The average age of vulva opening in the saline, blank virus, and interfering virus groups was 33.8, 34.1, and 37.9 days, respectively. The interference vector clearly delayed the age of vulva opening $(\mathrm{P}<0.01)$. 


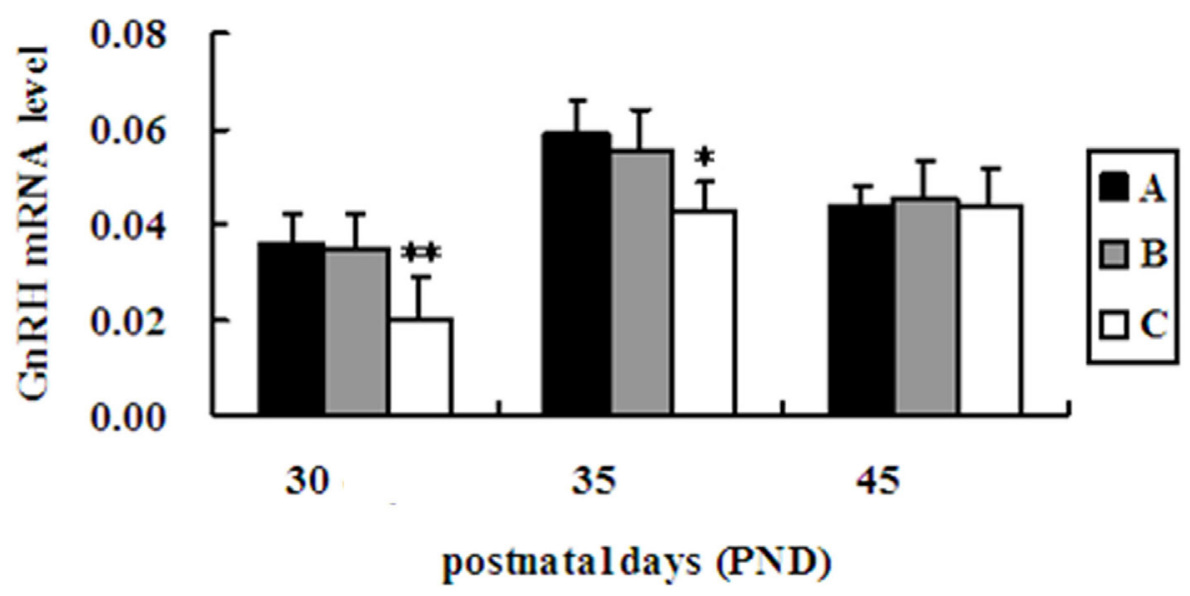

Figure 5. Hypothalamic GnRH mRNA expression at various stages of sexual development. A, B, and C represent the saline, blank virus, and interfering virus groups, respectively $\left({ }^{*} \mathrm{P}<0.05,{ }^{*} \mathrm{P}<0.01\right)$.

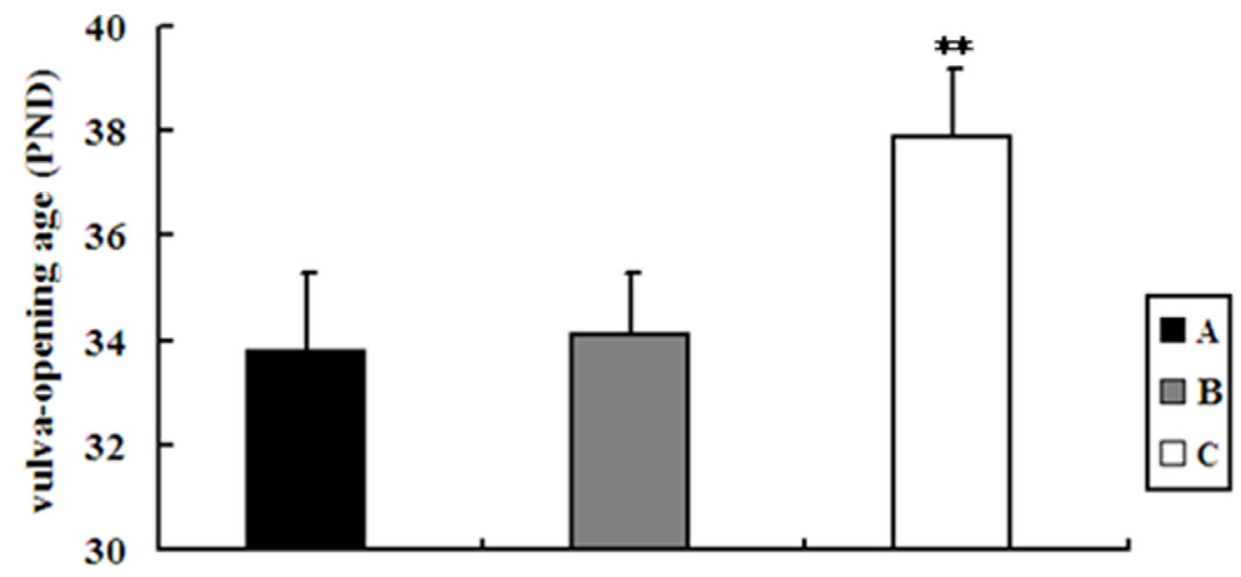

Figure 6. Vulva-opening age in each treatment group. A, B, and C represent the saline, blank virus, and interfering virus groups, respectively $(* * \mathrm{P}<0.01)$.

\section{DISCUSSION}

NELL2 is a secreted glycoprotein containing neural EGF-like repeats. The 140-kDa molecule is composed of 816 amino acid residues and contains a cleavable signal peptide as well as an N-thrombospondin 1 domain, 6 EGF-like domains, and 5 cysteine-rich chordin-like/ von Willebrand factor C domains (Oyasu et al., 2000). Postnatally, NELL2 mRNA is expressed throughout the rat brain. The highest expression levels are observed in the hippocampus and cerebral cortex, followed by the olfactory bulb and hypothalamus, and finally by the thalamus, cerebellum, and medulla oblongata. Many studies have shown that NELL2 plays an important role in nerve growth, neural differentiation, neural plasticity, synaptic transport, and vesicle 
release (Nelson et al., 2004; Choi et al., 2010; Nakamura et al., 2012; Munemasa et al., 2012).

Ha et al. (2008) found that NELL2 mRNA was highly expressed in the medial basal hypothalamus in female rats during the pubescent growth period. NELL2 levels in the medial basal hypothalamus region increase to a peak just prior to puberty (PND 22-30). Similar changes, although not of the same magnitude, were observed in the preoptic area (Campbell et al., 2005). These findings suggest that peak NELL2 levels are found in areas with a high density of spine synapses. Such synapses relay excitatory signals that trigger GnRH (Campbell et al., 2005). In addition, Ha et al. (2008) injected NELL2 antisense nucleotide into the cerebral ventricles of rats to prevent NELL2 synthesis. The medium in which these hypothalamic neurons were cultured contained reduced levels of GnRH. Therefore, GnRH secretion may be regulated by NELL2.

The lentiviral vector used in these experiments was a replication-defective retroviral vector that can infect non-dividing and mitotic cells. Lentiviral vectors are ideal for in vivo genetics experiments because of their long-term stability and reduced likelihood of initiating an immune response. Lentiviral vector-mediated RNA interference technology combines the advantages of a lentiviral vector with those of an RNA interference sequence that is specifically targeted to inhibit gene expression. These tools are effective in a variety of mammalian cells and numerous disease models (Nishitsuji et al., 2004; Gonzalez-Alegre, et al., 2005; Raoul et al., 2005; Rawls et al., 2007). Since Stewart et al. (2003) first reported the use of this technology, it has been used widely to study disease pathogenesis.

In this study, we found that NELL2 mRNA and protein expression decreased significantly in the group treated with RNA interference compared to controls at all 3 time points, suggesting that the lentivirus interference vectors constructed in this study inhibited in vivo NELL2 mRNA expression in a sustained, effective, and specific manner. Furthermore, at PND 30 and $35, G n R H$ mRNA levels were reduced in the experimental group, but not in either control group. After NELL2 downregulation, the expression of GnRH also decreased, indicating that NELL2 may affect the level of $G n R H$ mRNA and thereby affect the synthesis and secretion of GnRH.

mRNA levels were found to be related to 3 factors: DNA transcription into heterogeneous nuclear RNA, splicing, followed by transport from the nucleus to the cytoplasm and translation, followed by degradation. The results presented here suggest that NELL2 affects $G n R H$ transcription by influencing DNA transcriptional activity or mRNA stability. At 45 days, GnRH expression was similar in all groups, despite the reduced NELL2 expression observed. This finding is consistent with the hypothesis that the synthesis and release of GnRH is regulated not only by NELL2, but also by other factors such as kisspeptin and neurokinin B (Han et al., 2005; Plant et al., 2006; Wakabayashi et al., 2010; Nestor et al., 2012). We hypothesized that after long-term NELL2 suppression, kisspeptin and neurokinin B may compensate to promote the synthesis and release of $\mathrm{GnRH}$, which would in turn activate the hypothalamus-pituitary-gonad axis to initiate sexual maturation. The intracerebroventricular administration of $F U G W-N E L L 2$-microRNA delayed vulva opening in female rats, indicating that early inhibition of NELL2 neurons delays the onset of puberty. NELL2 plays an important role in onset of puberty in female rats. The detailed mechanisms underlying NELL2-mediated GnRH synthesis require further study.

\section{Conflicts of interest}

All authors have no conflict of interest. 


\section{ACKNOWLEDGMENTS}

Research supported by National Natural Science Foundation of China (\#81370686) and Shanghai Science and Technology Committee (\#12411950403, \#12411950400), (\#009411963100).

\section{REFERENCES}

Bringer J, Lefebvre P and Renard E (1999). Nutritional hypogonadism. Rev. Prat. 49: 1291-1296.

Campbell RE, Han SK and Herbison AE (2005). Biocytin filling of adult gonadotropin-releasing hormone neurons in situ reveals extensive, spiny, dendritic processes. Endocrinology 146: 1163-1169.

Choi EJ, Kim DH, Kim JG, Kim DY, et al. (2010). Estrogen-dependent transcription of the NEL-like 2 (NELL2) gene and its role in protection from cell death. J. Biol. Chem. 285: 25074-25084.

Duan WF and Li P (2010). Analysis of expression of NELL2 and GnRH mRNA in hypothalamus of female SD rats at different sex development stages. J. Shanghai Jiao Tong Univ. 30: 296-298.

Gonzalez-Alegre P, Bode N, Davidson BL and Paulson HL (2005). Silencing primary dystonia: lentiviral-mediated RNA interference therapy for DYT1 dystonia. J. Neurosci. 25: 10502-10509.

Ha CM, Choi J, Choi EJ, Costa ME, et al. (2008). NELL2, a neuron-specific EGF-like protein, is selectively expressed in glutamatergic neurons and contributes to the glutamatergic control of GnRH neurons at puberty. Neuroendocrinology 88: 199-211.

Han SK, Gottsch ML, Lee KJ, Popa SM, et al. (2005). Activation of gonadotropin-releasing hormone neurons by kisspeptin as a neuroendocrine switch for the onset of puberty. J. Neurosci. 25: 11349-11356.

Harris GC and Levine JE (2003). Pubertal acceleration of pulsatile gonadotropin-releasing hormone release in male rats as revealed by microdialysis. Endocrinology 144: 163-171.

Munemasa Y, Chang CS, Kwong JM, Kyung H, et al. (2012). The neuronal EGF-related gene Nell2 interacts with Macf1 and supports survival of retinal ganglion cells after optic nerve injury. PLoS One 7: e34810.

Nakamura R, Nakamoto C, Obama H, Durward E, et al. (2012). Structure-function analysis of Nel, a thrombospondin-1like glycoprotein involved in neural development and functions. J. Biol. Chem. 287: 3282-3291.

Nelson BR, Claes K, Todd V, Chaverra M, et al. (2004). NELL2 promotes motor and sensory neuron differentiation and stimulates mitogenesis in DRG in vivo. Dev. Biol. 270: 322-335.

Nestor CC, Briscoe AM, Davis SM, Valent M, et al. (2012). Evidence of a role for kisspeptin and neurokinin B in puberty of female sheep. Endocrinology 153: 2756-2765.

Nishitsuji H, Ikeda T, Miyoshi H, Ohashi T, et al. (2004). Expression of small hairpin RNA by lentivirus-based vector confers efficient and stable gene-suppression of HIV-1 on human cells including primary non-dividing cells. Microbes Infect. 6: 76-85.

Oyasu M, Kuroda S, Nakashita M, Fujimiya M, et al. (2000). Immunocytochemical localization of a neuron-specific thrombospondin-1-like protein, NELL2: light and electron microscopic studies in the rat brain. Brain Res. Mol. Brain Res. 76: 151-160.

Palmert MR and Boepple PA (2001). Variation in the timing of puberty: clinical spectrum and genetic investigation. $J$. Clin. Endocrinol. Metab. 86: 2364-2368.

Plant TM, Ramaswamy S and Dipietro MJ (2006). Repetitive activation of hypothalamic G protein-coupled receptor 54 with intravenous pulses of kisspeptin in the juvenile monkey (Macaca mulatta) elicits a sustained train of gonadotropin-releasing hormone discharges. Endocrinology 147: 1007-1013.

Raoul C, Abbas-Terki T, Bensadoun JC, Guillot S, et al. (2005). Lentiviral-mediated silencing of SOD1 through RNA interference retards disease onset and progression in a mouse model of ALS. Nat. Med. 11: 423-428.

Rawls AS, Gregory AD, Woloszynek JR, Liu F, et al. (2007). Lentiviral-mediated RNAi inhibition of Sbds in murine hematopoietic progenitors impairs their hematopoietic potential. Blood 110: 2414-2422.

Seminara SB, Dipietro MJ, Ramaswamy S, Crowley WF Jr, et al. (2006). Continuous human metastin 45-54 infusion desensitizes $\mathrm{G}$ protein-coupled receptor 54-induced gonadotropin-releasing hormone release monitored indirectly in the juvenile male Rhesus monkey (Macaca mulatta): a finding with therapeutic implications. Endocrinology 147: 2122-2126.

Stewart SA, Dykxhoorn DM, Palliser D, Mizuno H, et al. (2003). Lentivirus-delivered stable gene silencing by RNAi in primary cells. RNA 9: 493-501. 
Terasawa E (2006). Postnatal remodeling of gonadotropin-releasing hormone I neurons: toward understanding the mechanism of the onset of puberty. Endocrinology 147: 3650-3651.

Wakabayashi Y, Nakada T, Murata K, Ohkura S, et al. (2010). Neurokinin B and dynorphin A in kisspeptin neurons of the arcuate nucleus participate in generation of periodic oscillation of neural activity driving pulsatile gonadotropinreleasing hormone secretion in the goat. J. Neurosci. 30: 3124-3132.

Zhou SS and Li P (2011). Construction of eukaryotic expression vector and microRNA expression plasmid of NELL2 gene and their biological effects in vitro. J. Shanghai Jiaotong Univ. 31: 177-181. 